\title{
Papers
}

\section{Managing retention - Who does it well?}

Received (in revised form): 24th December, 2006

\begin{abstract}
Merlin Stone
is one of the UK's most experienced consultants, lecturers and trainers in CRM, database marketing and customer service. He is the author of many academic and professional papers and 30 books on marketing and customer service. He is a founder fellow of the Institute of Direct Marketing and a fellow of the Chartered Institute of Marketing. The Chartered Institute of Marketing listed him in 2003 as one of the world's top 50 marketing thinkers, while NOP World nominated him in 2004 as one of the 100 most influential individuals for their input and influence on the development and growth of e-commerce and the internet in the UK over the last 10 years. He is a director of Nowell Stone Ltd, an organisational development and consulting company specialising in database marketing, CRM, e-business and associated areas of customer service and IT. He has also pursued a full academic career, involving senior posts at various universities and has a first class honours degree and a doctorate in economics. He is now Visiting Professor at these universities: Brunel, De Montfort, Luton, Portsmouth, Southampton Solent and The West of England.
\end{abstract}

\section{Dak Liyanearachchi}

is Director, Consumer Division, LBM, one of the UK's leading suppliers of customer management and direct marketing services. He was recently appointed to this post, in which he heads LBM's new consumer data and consulting division. Before taking up this post, he was the Global Business Development Director at dunnhumby and before that, Operations Director at Catalina Marketing. His consultancy work includes experience with Tesco, Asda, Somerfield, Hewlett Packard, Cadbury Schweppes and Coca Cola. He has a BSc (Hons) Business Information Systems degree from the University of Central England.

Keywords customer retention, customer information, contact centre, customer value, customer contract

Abstract This paper investigates some aspects of customer retention, in particular the role of customer data and contact centres. It investigates the reasons for problems in managing customer retention, from definition and strategy to operational issues. It describes some recent qualitative research carried out by the authors and shows how different companies are at different stages of maturity in retention management. Journal of Database Marketing \& Customer Strategy Management (2007) 14, 90-103.

doi:10.1057/palgrave.dbm.3250042

Merlin Stone Nowell Stone Ltd, 41-42 Foley Street, London W1W 7TS, UK Tel: +44 7968271937 e-mail: merlin@nowellstone. com

\section{DEFINING AND MANAGING RETENTION}

A few years ago, ${ }^{1}$ one of the authors (Merlin Stone) published some research on customer retention. It showed that even though most companies put customer retention as a top priority, most had no definition of customer retention, and most of those who did have a retention definition did not have a measure that corresponded to it. Finally, when we looked at what companies who claimed to be measuring retention were actually measuring, it mostly turned out to be something different - like sales levels from existing customers. This was despite the fact that the research was based on clients' own assessment, which is normally much more positive than reality!

In various projects that we have been involved in lately, we have been surprised at how easy it is for a company to lose its way 
Table 1: The retention (or attrition) journey

\begin{tabular}{|c|c|c|}
\hline Stage & Good outcome & Poor outcome \\
\hline Pre-acquisition & Enquiry & Contract or brand problems \\
\hline Acquisition agreement & Verbal agreement & Decide not to proceed \\
\hline Contracting & Payment received & Not taken up \\
\hline Welcoming & $\begin{array}{l}\text { Receive or respond } \\
\text { to welcome action }\end{array}$ & $\begin{array}{l}\text { Not receive and/or respond } \\
\text { to welcome action }\end{array}$ \\
\hline Early life & Early use pattern understood & Early problems \\
\hline Early maturity & Early problems resolved & $\begin{array}{l}\text { Mature problems due to } \\
\text { more regular or advanced use }\end{array}$ \\
\hline $\begin{array}{l}\text { Pre-anniversary } \\
\text { or contract end }\end{array}$ & Commit to renewal & $\begin{array}{l}\text { Price or product } \\
\text { benchmarking }\end{array}$ \\
\hline $\begin{array}{l}\text { Anniversary or } \\
\text { contract end }\end{array}$ & Renew & Switch \\
\hline Renewal & Renewal achieved & Begin journey with competitor \\
\hline
\end{tabular}

in retention management, even when it has a reasonably clear definition of retention, a well-established churn prediction model and also a strong corporate focus on retention because of its proven high impact on profitability. The businesses we are discussing here are all contract businesses. in which customers are recruited for an initial contract, and then after a period are free to move on to other suppliers, of which there are plenty. The problem concerns the location of data on the attrition process. The reasons for attrition are easy enough to identify, particularly when you take the customer journey approach - examining all the stages in the recruitment process from first contact through to the time when the contract expires and the customer is free to move. The reasons range from poor customer service in the contact centre or other channel, financial issues - such as affordability or whether the customer was on the right-level contract in the first place, technical issues (eg system or equipment failure) and the like.

\section{THE RETENTION (OR ATTRITION) JOURNEY}

This process is shown in Table 1, along with examples of the good and bad things that can happen at each stage - these are the things we need to know about or, to put it another way, the things that trigger the creation of the data we need, to manage retention better.
In many cases, as the diagram shows, attrition is not an instant process, but takes place as a result of a series of events (even if these events occur over a short period). For example, a customer may call to query the price being charged, enter a dialogue with the contact-centre agent about alternatives, commit to a lower cost contract, and then call again if still unhappy with the contract. An equipment or network failure may be evidenced through a series of calls and other events, including field visits, delayed payments and the like. A customer regarded as being at risk of attrition (either because they have been identified as such through application of churn prediction model, or because of the severity of a problem raised in a call) may have been escalated to an attrition prevention team, where a new set of processes starts. Meanwhile, regular customer satisfaction surveys may be in place, picking up early signs of discontent.

\section{WHERE ATTRITION STARTS AND ENDS}

Attrition can occur at all stages of the customer management cycle conceptually, it can start even before acquisition, in the case of the customer who joins with the intention to leave. But other examples include the customer who joins insecurely (perhaps the contract has problems), the customer who joins, but at less value than agreed, and even the 
customer you think has joined — but has not! Diagrams like the above help you identify the different ways in which attrition can occur. We call the diagram 'micro-retention diagram', because it focuses on every possible step that can occur in the attrition journey - in practice, most micro-retention analyses would be much more detailed, and show different tracks running in parallel rather than just a central track with outcomes.

\section{DATA ON ATTRITION}

All this means that data on the attrition journey on an individual customer is likely to be scattered over many systems - those supporting the contact centre, financial, field support, marketing, mailing, for example. In the most advanced companies, these may all be on one system, but this is rare - even rarer if we are talking about real-time integration of such data. If a customer satisfaction measurement process is in place, if it is undertaken on the market research model, narrowly sampled but deep, with customers remaining anonymous, this is unlikely to be of much use in individual customer attrition prediction, though it will be useful in understanding attrition and for attrition policy-making. Where a company is using online or computerised systems for satisfaction measurement to reach a much larger number of customers, it is feasible to use these data in individual attrition management. Once again, this is rare.

\section{SATISFACTION AND RETENTION}

One of the most interesting issues here is that old chestnut - the relationship between satisfaction and loyalty. Most companies we work with have discovered that the relationship between customer experience and customer attrition is a complex one that cannot be summarised by the customer simply in terms of degrees of satisfaction. In one interesting case recently, we came across a company using degrees of delight in a questionnaire. We were sceptical about this, but actually, it did work as a predictor of attrition, so our scepticism was unjustified. However, we are still not sure what customers meant when they said 'slightly delighted' or 'not very delighted'. Another company was very focused on the proportion of customers who said that they were very satisfied, even though all the evidence was that there was no correlation between this and any other business indicator - retention, profit, etc.

\section{ATTRITION PREDICTION}

The search for a Holy Grail simple predictor of attrition is, however, still very active in large companies despite the point made above that attrition is a complex journey, and that what is in the customer's mind is represented in various ways (satisfaction, recommendation or advocacy and confidence). So, we do not believe in a Holy Grail. We would like to see more companies with contractual business such as the ones described in this column using online (web, telephone or text) measurement techniques covering a greater variety of indicators (not just satisfaction levels) for a higher proportion of customers (particularly new customers, where attrition is usually concentrated), with the data from these measurements being managed routinely into immediate churn prediction and prevention activity - using all customer contact channels, not the inevitable phone call from a contact centre to sense whether the customer is really going to leave.

\section{CUSTOMER JOURNEYS AND CUSTOMER EXPERIENCE}

Managing retention is just one aspect of managing the customer's journey, and part of this is managing the customer's experience. Customer experience management is now the focus of many marketing, sales and service projects, particularly in companies with large contact centres or those using several different 
customer management channels. Customer experience management focuses - or should focus - on how to manage everything that contributes to the customer's experience of your products, their associated services, the promotional campaigns through which they are offered, the brand within which they are provided, and things you control less directly - how the product or service is offered through or with third parties, expectations generated by you, by media coverage (by PR), by other customers (through word-of-mouth) and even by competitors. It is an integrating perspective, crossing boundaries of marketing, sales and service, and of different channels of communication and distribution. It has a broader scope than contact management. But its integrating perspective is too easily abandoned. You often hear companies discussing how they manage customers' contact-centre experience. When I hear that, we look out for disconnects between the contact centre and other channels, such as direct mail, branch service operations and so on. However, focusing on customer experience- even just in a contact centre - is beneficial. It forces a strong focus on the customer. It reminds us that - particularly in service industries most experience is not of marketing or sales efforts, but of our operations. I avoid the word 'service' here, because that makes you think of customer service.

For example, if you are a customer of a bank, a mobile phone company or an airline, your experience of an airline is mostly of operational things. You make a call on a mobile phone. Have you got reception? Is it good? Can you get through? Does the call drop? If it does, is it automatically restored? If lost, are you credited on your bill? If you try to make a call and fail, is the call recipient notified by their company? If you are a busy professional, you might experience operational practices of the phone company tens, even hundreds of times a day (several times per call). If you pay through your bank branch, do you queue? How long? Do you have to fill in a complex form? Is the payment made on time? If you take a flight, do your tickets arrive on time, or does e-ticketing work? Do you have to queue? Do you have access to a lounge? Does the flight take off and land on time? Are the cabin crew any good? The food?

\section{USING CUSTOMER EXPERIENCE DATA}

In the best companies, data on at least some aspects of customers' experience of operations are used routinely to manage them. Dropped calls re predictors of mobile phone customer attrition and are used by some companies in an integrated way, that is, by being copied to a data warehouse to be mined along with the other data to identify valuable customers most likely to leave. These experiences, however, are part of a wider experience, the customer journey. Here, the focus is on time. A journey is a time slice through customer experience. Experiences are a sequence of events. There are many sequences or journeys, usually interrelated. The shortest include web visits, telephone enquiries and even opening direct mail. These may be part of a longer sequence - product or service acquisition, themselves part of a product-use journey. In the middle are contract-length journeys, for example, experience of a mobile phone company or car insurer for the contract period. At the other extreme are life-stage and life-time journeys, such as the journeys many people have with life insurers, banks and retailers, with companies' customers tending to be loyal for long periods, for example, automotive, airline and holiday. One of the longest journeys of all is the category journey. The longer the journey, the closer the customer's feelings about it tend to be about the brand. But many customers are intelligent enough to recognise the difference - hence the complaint of the loyal frequent flyer who 
has years of intense flying, followed by years of inactivity, which leads to the airline downgrading them to the bottom tier of the frequent flyer scheme, and then again by resumed high activity. The common complaint? Don't you remember I used to be Gold? The answer is, no. It is not on most airlines' customer-facing systems, though stored on their databases.

Managing customer journeys in an integrated way is an aspiration that demands a big data integration effort - over time, over different activities - operational, marketing, sales and service. It is not always worth it. But it is for some, and can be a competitive differentiator. Typically, market research will tell you if it is likely to be worth it, and whether your best customers will reward you for it by staying longer and buying more.

\section{EXPLORING THE IDEA OF RETENTION}

Retention is an interesting concept, very different from acquisition. When we acquire a customer, we know that the customer is doing business with us now (though acquisition is really too aggressive a term, implying ownership and we never own our customers) and was not before, though of course we may have won the customer back, and if our data are of poor quality, we may count as an acquisition, a customer who was actually doing business with us! Retention is not always an action (except in the case of contract or product renewal). It is often just a state - the customer continues doing business with us as before. Doing well in retention is a relative matter - we can improve over time, but perhaps more importantly, we can do better than our competitors, particularly if we focus on retaining the best customers, perhaps leaving our competitors with lower quality customers.

Customer attrition is caused by a variety of factors. These include things we cannot control, such as customer exit from the category (perhaps because their life cycle moves on), although even here we might be able to extend their use of the category. Poor communication, service or customer experience are some of the main causes of attrition, as is poor management of the customer across different channels or media. But we may also lose customers because of a weak retention proposition. Staff play a critical role in retention, particularly in contact centres, so much so that staff retention is correlated with customer retention - both ways. Giving staff a tough retention job often leads to more staff attrition, while having a high staff turnover often reduces the quality of contact-centre work, increasing customer attrition. The internet has also affected customers' propensities to search for and evaluate competitive propositions, and then to switch. Aggregator and switching sites are just the latest wave of change in an internet which is increasingly being run by customers (the central idea of Web 2.0).

\section{MANAGING RETENTION}

In our work over the last few years, we have found that improved retention can be put down to the combination of improved retention capability (data, systems, processes, measures, etc) and better deployed capability (eg consistent objectives, strategy and incentives). A balanced, steady programme of change seems to work better than dramatic progress in one or a few areas. Strong change management disciplines help - and these are less widespread than they should be - although in customer service departments, they tend to be stronger than in marketing and sales. Perhaps, most important of all is self-awareness or honesty about the company's current position not just how well it manages retention but how well it manages change with retention as the objective, how well it develops and deploys its retention capability.

Some companies have found that retention is improved by consistent 
partnership with outsourced suppliers of data, data management, insight and contact management, because the supplier provides a focus that is often lost in the company's normal turmoil. This kind of partnership should lead to mutual, secure learning. It can also put the spotlight on process weaknesses, as the supplier's focused processes try to interlock with processes on the client's side that are not retentionfocused.

\section{UNDERSTANDING IS THE KEY}

Understanding is the key to good retention work - defining what retention is, understanding why it occurs and what can be done with it, particularly in a multichannel, multi-product situation. Financial aspects are important - this means understanding the relationship between acquisition, retention and profit. Prediction is important too, and for this good customer insight is required, using not only the classic data sets of database marketers, but also research, customer satisfaction analysis and customer given data. This latter category is particularly tricky, as you need to learn what data can reasonably be asked of different kinds of customers, and how much truth is told, rather than fiction. Trigger analysis has proved very valuable in the absence of data on customers' intentions, though it can normally tell you only what customers have just done or are about to do, rather than what they are planning.

\section{STRATEGY AND IMPLEMENTATION}

At the strategic level, good retention practice depends on having a retention strategy, one which has been demonstrated to be critically important to the business, and which is owned by someone who has the authority and budget to do something about it. This strategy identifies which customers or types of customers are worth retaining and which can be retained cost- effectively. The strategy must be properly implemented, which means that it should be defined in a shared way, be understood by all involved in its implementation, and be targeted in a way that is consistent with other policies (eg product sales volumes and profit), actionable and measurable, with agreed governance in relation to other objectives, for example acquisition, customer development. A tested and remembered history of retention activity is central to much of this.

Retention is normally managed better in companies with a history of stability in marketing (product and customer), service planning and delivery, across all channels. This is because it takes time to learn what works, and to carry out tests. It also takes customers time to learn how to make use of the retention proposition.

Organisationally, we have found that a post or a section dedicated to retention does work, but it must be deployed carefully to avoid trying to retain customers who do not want to leave (who would have if the retention target overrode the profitability target). Metrics and targets need to be medium term so that results of retention activity can be understood. Where relevant, they must be closely related to the typical cycle of ownership, use or contract.

\section{BACK TO DATA}

As the above makes clear, one of the keys to managing customers - especially the never-ending retention journey - is data. Some companies know more about new customers than existing customers, because a lot of data were brought together to support the acquisition process. Often data about existing customers is variable in quality and, of course, recency. Our understanding of customer behaviour over the customer management cycle is often patchy, largely because there is so much to know, and the data appear in many different ways, in many media and channels. 
So, we decided to do a small piece of research. We used a simple e-mail survey to ask a number of very large companies the following questions:

1 Does your company have an explicit or implicit customer data planning and management process for retention and development, and if so, who owns it and how is accountability for ownership made effective?

2 If so, what are its main features?

3 In what respects would you say your company has an agreed customer data strategy for customer retention and development?

4 To what extent does your company have an agreed customer retention and development methodology?

5 What are the main strengths and weaknesses of your company's approach to its use of customer data in retention and development?

6 How does your company define customer data quality?

7 What is your company's approach to managing the quality of the customer data it uses for retention and development?

8 What is your company's approach to the governance of data used in retention and development?

9 What are the main people issues you face in relation to customer data management?

10 What role, if any, do external suppliers play in your management of customer data? How important is this role in retention and development, and what are the main strengths and weaknesses of your arrangements?

Ten companies responded. The aim was not to produce a fully representative picture, but to explore the situation, by putting the data from the research together with data from our involvement as consultants with a number of other very large companies. We subjectively identified six segments:

- The nowhere man

- The novice

- The guru-follower

- The developer

- The obsessive and

- The professional.

Nowhere men follow other indicators (typically gross sales/new customers), even though they know retention is important. Some have tried, but data and organisational problems proved insurmountable. This may be due to a 'silo' mentality in multi-product and/or multichannel business, power struggles or simply organisational churn.

Novices are aware of the general importance of retention and need to work on it, but they do not have the data or organisational infrastructure to allow it. They are typically working on their first serious approach to retention.

Guru-followers are aware of the financial importance of retention, but are typically focused on some other measure of success in customer management, such as customer satisfaction, net recommendation or some other guru-derived measure. Data development of this indicator is therefore skewed in direction. The data are, however, often surprisingly weak, for example with small sample sizes used to measure key indicators. There tends to be over-reliance on indicators with unproven connection with main business variables (especially not with profit).

Developers bring retention and/or loyalty into sharp focus. Their conflict with sales volume or similar targets is still evident, but they have done or are doing a lot of work to understand the reasons for attrition, what can be done to stop it and the return on investment achieved by improved retention. Data requirements for retention management are defined or being defined using good analysis. Their data and analysis 
work tend to focus on how to target for retention (net/gross value) and segmentation for likely attrition. They have defined organisational accountability for retention, though there will still be discussions about the right approach, and they may be experiencing problems in making accountability stick at different levels. Data quality work is well under way, with some agreement/work on definitions, priorities, costs, benefits and benchmarks. Data stewardship accountability is typically not allocated, though the need for it is understood. Typically, a lot of learning is taking place about how to manage retention, such as the role of inbound and outbound communications, the use of different channels and the value of data quality. Developers experience some problems recruiting the right people to work on data, but are having early ideas on the internal development and training of such people. Their use of outsourced data management and analysis services is developing, and they are beginning to understand the issues of quality, process stability and speed.

Obsessives believe that retention is king. This is not surprising, as they are concentrated in high-churn industries often with a contractual or annual renewal focus, where customer recruitment is very expensive. Obsessives are particularly common where there are a few big players 'bidding' for customers. In this situation, the financial rewards of reduced attrition are high. Attrition prediction is normally sharply focused. However, all this can lead to an over-strong set of consumer and staff incentives, such that customers are 'bribed' to stay, and many retained customers are less profitable than new customers. Outsourced data management and analysis services are typically focused on retention prediction, particularly on improving data quality and attrition prediction, but most of these companies are yet to learn how to use contact-centre partners in this area.
Professionals have learnt to balance retention with acquisition and development, often within a group or department, for managing customer value, or something similar. The marketing plan reflects this balance. Budgets are allocated accordingly, as a result of this marketing plan. Testing is used extensively to determine the optimum balance of activity. This approach is common in mono-line or focused-line or direct-only businesses (eg credit cards, general insurance and mail order).

Segments needing retention focus are well defined, usually based on customer net value modelling. Mature predictive models use current and past data, with some companies starting to use integrated optimisation to determine the combination of customer recruitment, retention and development plans, and product and channel plans. Targets, measures and reporting for retention, acquisition and development are determined consistently and jointly. Some of these companies are experimenting with customer-given data on plans/intentions. In these companies, there is clear accountability for loyalty/ retention (and acquisition, development) and total clarity on the data requirements to support these tasks. Data (and indeed the whole retention approach) are never considered perfect, even if it is what other companies would give their eye-teeth for, and this is because these companies are usually locked in a battle for customers with other companies just like them. There is a clear data development and governance process running at all levels, from policy to contact centre, with precise roles for outsourced data management/ analysis.

The number of professionals is slowly increasing in our view, and many companies we research or work for are developers and making good progress. The situation is certainly much better than it was a few years ago. In most companies, however, there is still one big problem. 


\section{THE STAFF PROBLEM}

One of the themes that recurred in the research was the problem of staff churn, particularly, but not solely, at the senior level. This leads to constantly changing focus in marketing, sales and service policy and implementation. Knowledge is lost. Loyalty and retention projects are stopped and started. It is hard to secure the commitment of the front line to new policies, which they believe will not last long and are inherently more complex, particularly when they are accompanied by inconsistent communication and incentives. This situation is often combined with process weaknesses in data, marketing, sales and service, with the inevitable results that attrition and retention are less well understood than they should be. Action is weaker as a result.

\section{THE CONTACT CENTRE IN RETENTION}

So far, we have outlined some of the definitional, methodological and practical issues involved in managing retention, and described the preliminary results of our research into the role of the contact centre in retention. Now, we turn to the role of contact centres in customer retention.

\section{THE CONTACT CENTRE - A PROCESS TECHNOLOGY}

We should not expect retention work in contact centres to be a refined art. That is because contact centres are a relatively new process technology. For their users, they are a way of doing things, not a product. They are themselves based on product and process innovations in IT, telecommunications, marketing, service and human resource management. The fascinating thing about technologies, whether process or product, is that they are at their most innovative just before they are replaced. That is because they are challenged by the next technology, and respond - in the case of service call centres, the challenge comes from the Internet in all its forms.

The best example is steam locomotives, which went through many innovations and modifications to improve reliability and energy efficiency, just before being completely replaced by diesel-electric locomotives. To take another example, photocopiers are now document centres, with astonishing features, but most people use them rarely, instead of exchanging documents digitally.

In the same way, voice contact centres are improving radically as they are about to transform into a true all-media contact centre, at least here in the wired-Western economies. We can now install them anywhere in the world, transfer complex data to and from them quickly, and manage customers much more appropriately, with much better returns on our budgets. In some situations, however, the web is a better solution and represents the next process innovation, sometimes working with contact centres, sometimes in competition with them and sometimes both. The next generation - the integrated web and voice centre - is already with us, with voice being used when the web fails and/or the customer or supplier needs to delve into issues that cannot be resolved on the web. However, contact centres continue to grow in quality and number, as the web transfers more and more business from older channels such as sales forces and retail outlets. The more direct customer contact there is, the more contact centres will need to validate customers and transactions and resolve problems.

Of course, every wave of change has leaders and laggards. These may be whole companies, or different functions within one company, or even whole countries. Companies that have been using voice contact centres mainly to patch poor processes tend to resist the next wave of innovation. Meanwhile, the innovators those who are getting much more value out 
of contact centres - have realised that they can get even more value for themselves, and give more to customers, if they could move beyond the contact centre into a world of integrated customer management. The innovators have moved away from targeting contact centres on productivity. They have done the data engineering and analysis needed to get the right data, properly profiled, to contact-centre staff who are handling customers. They have prepared a hierarchy of offers, matched to different customer profiles, to enable the value of the call to be maximised and to help the customer choose the right product.

\section{HOW CUSTOMERS VIEW THE CONTACT CENTRE}

Last year, one of the authors (Merlin Stone) was asked to appear on BBC Breakfast TV to comment on a recent report from NetReflector on differences in national attitudes to contact centres. The survey that was carried out in USA, Australia, Brazil, Canada, China, Russia, UK, France and Germany shows that in nearly all the countries, the most preferred way to contact the customer service departments is via the telephone (66 per cent preferred this method). The next most popular method is e-mail (25 per cent preferred this method). A fairly high percentage of customers in Russia prefer to do it via chat $(27$ per cent, compared with 3 per cent elsewhere in the world). Not surprisingly, the focus of the $\mathrm{BBC}$ was on problems with service, but call centres are - in marketing terms - a relatively new approach, with a 30-year history instead of retailing's 200 years (or 2000 , some would say). Also, technology is changing so fast and customers' expectations are rising so quickly that it is hard for contact-centre management to keep pace. So it is not surprising that service is of such a variable quality, even though customers anywhere have simple requirements, as the NetReflector survey shows. All over the world, the best way to satisfy customers in contact centres is to ensure that they interact with knowledgeable service agents who resolve the customer's problem in one interaction. Outsourcing to countries whose first language is not that of the customer's country has, however, caused problems. In the US, Australia and UK, customers' top frustration about poor customer service is: 'Their accent makes it too difficult to understand them.' The BBC seized on this, though it was pointed out that this problem was usually due to bad, rapid outsourcing and focusing on cost and not on quality. Respondents (27 per cent) indicated this as a top frustration, while in Brazil, France and Germany, customers' top frustration is: 'They make me wait ages on the phone' (49 per cent of respondents indicated this as top frustration). In China and Russia, the customers' top frustration was: 'They are not up to speed technologically' ( 24 per cent of respondents indicated this as top frustration) and 'They are rude or condescending' (31 per cent).

So why do so many contact centres find it hard to deliver? To find the answer to this, we can use the Merchants Global Contact Centre Benchmarking report 2006. We need to treat these data carefully, as it is based on the opinions and perceptions of contact-centre management, but it is the best we have. It is also a global study, skewed towards English language respondents, with large UK, US and South African participation. The survey is in English, and the high South African participation is explained by the involvement of Dimension Data, the South African company that owns Merchants, but 44 per cent of the participants are European. The average customer base of respondents is 9.7 million (but 48 per cent of respondents have fewer than 1 million). Over 75 per cent have more than one contact centre. The most important trend highlighted by the report is that customer satisfaction is playing a much more important part in development strategy for 
contact centres. The top three items in contact-centre strategies are customer satisfaction, quality/process improvements and technology strategy. As we know from our work, the relationship between customer service, customer satisfaction, loyalty and profit is not a clear one, however, with many companies discovering that many of their most satisfied customers leave for reasons other than customer service (product and price, eg in telecommunications and financial services). So it is not surprising that contact centres that focus just on customer satisfaction come under pressure for cost reasons - the business case for increased investment in the contact centre is not clear.

That is why segmentation is important - deciding which customers need to be served better or faster. This can be achieved by organisational structure. The Merchants report indicates that 21 per cent of contact centres are organised around customer/ market segments, compared with 17 per cent around products/product groups, 12 per cent functional (sales, service and marketing), 12 per cent all purpose and 33 per cent a mix of these options. Interestingly, 44 per cent of respondents are conducting or planning to conduct formal segmentation of their customer base specifically for contact centre, and 11 per cent of respondents are using more segments in their contact centre than in the rest of the organisation, indicating a trend towards differentiation between service strategies. Meanwhile, cost-reduction pressures continue, with the report signalling a strong trend towards selfservice and process optimisation. Technology is helping, with the survey showing that voice recognition technology has matured nicely and is replacing other approaches.

Our conclusion - it is not always easy to manage contact centres so that customers enjoy calling them. But those who are old enough to remember the access-less world of customer service 30 years ago should count their blessings as consumers. Real progress has been made in helping customers buy products and receive service, which is why they still prefer the telephone. Contact-centre technology is still changing rapidly, and many companies are still coming to grips with this relatively recent innovation. However, when companies learn to manage voice, web, chat, mobile text and e-mail in an integrated way, we can expect customers to be happier with how relationships between them and their suppliers are managed.

\section{OUR RESEARCH}

Our research into data in customer retention suggests that one of the keys to customer retention in contact centres is proper customer data management. But of course, having the data to support contact centres is only one part of the jigsaw. To find out more, we repeated our research, using the same approach, this time focusing on how companies are managing their contact centres for retention. We asked the following questions:

1 Does your company have an explicit or implicit planning and management process for customer retention and development in contact centres, and if so, who owns it and how is accountability for ownership made effective?

2 If so, what are its main features?

3 What are the main causes of customer attrition in your business?

4 Do you predict attrition, and if so how?

5 Do you deploy retention activity to prevent attrition, and if so how, and how is the effort split between different channels or media?

6 If you have a contact-centre retention strategy, how is it implemented?

7 What are the main strengths and weaknesses of your company's approach to its use of contact centres in retention and development? 
8 How does your company define success in customer retention and development in the contact centre?

9 What are the main people issues you face in relation to contact-centre work on customer retention and development?

10 What role, if any, do external suppliers play in your use of contact centres in managing customer retention or development? How important is this role and what are the main strengths and weaknesses of your arrangements?

We followed the same approach in presenting our research, and taking the nine responses we received by combining them with our conclusions from our consulting experiences with similar companies. We found it easy to use the same categories that we used for data research - it seemed to be a natural fit. The segments were:

1 The nowhere man

2 The novice

3 The guru-follower

4 The developer

5 The obsessive and

6 The professional.

Of course, a company, may occupy different segments for data and contact centres. For example, contact-centre capabilities might not be exploited because of poor data management, or vice versa, or because of different 'silos' for data management and contact centres.

The nowhere man has customers calling, but either those answering are not organised in what we would recognise as a contact centre, or the contact centre is run purely on customer service lines. This would be indicated, for example, by problem resolution being one of the top indicators. Efficiency is also a dominant measure. This situation is common where the main role of telephone contact is to support other (dominant) channels, for example sales force, retail or web.
The novice is introducing the 'marketing disciplines' of the contact centre to add to existing customer service disciplines, typically with some outbound selling and early experiments with selling on inbound. There is dawning understanding of the role of the contact centre in retention, but no management of this role, for example strategy, training, targets, scripts, optimisation, etc. Efficiency still dominates as a key performance indicator. The customer data and customer insight infrastructure is relatively weak, for example no access to single/less-fragmented view of customers, no analysis to identify the appropriate retention proposition. For these reasons, the novice encounters the classic problems of cross-channel differences in their view of customer and/or the proposition proposed. For many of these companies, the contact centre is still the minor channel, with other channels (sales force and retail branch) not being concerned with integration (or even about retention).

The guru-follower is aware of the financial importance of retention, but some other guru-derived key performance indicator for service is king, such as customer satisfaction, customer delight or recommendation/ promotion. Data development is skewed in the direction of this indicator, but the quality of the data is often surprisingly weak, for example, small sample sizes used to measure the key performance indicator, which usually has no proven connection with main business indicators, and especially not with profit. All this leads the contact centre to exposure to criticisms on efficiency grounds, so the likely result is that contact-centre performance measurement will be raised as a board-level issue. This, in turn, can lead to a focus on new business or up/cross-sell, rather than retention, in order to prove that the contact centre delivers the appropriate return on investment.

For the developer, retention and loyalty are coming into sharper focus, although conflict 
with sales volume or similar targets is still evident. The developer is doing a lot of work to understand the reasons for attrition, what can be done to stop it and the return achieved by retention prevention. Targeting work focuses on the (net or gross) value of retained or lost customers and segmentation for likely attrition. Data work on retention is typically progressing well and increasing integration with contact-centre work. There is defined organisational accountability for retention, but the company will still be having discussions and problems in making it stick at different levels. There is early work in the contact centre to improve retention, through retention proposition, scripting and retention targeting. There may be some learning concerning the role of inbound and outbound, and the use of different channels. Some of those customers who use outsourced suppliers for contact-centre work will be in discussions with these suppliers on how they can progress from helping with customer acquisition or up/cross-sell to working on retention.

In a way, the obsessive is a close relative of the guru-follower, because of the strength of focus, but in this case the focus is correct. Retention is king. These companies are most common in high churn industries - often those with a contractual/annual focus to relationships, where customer recruitment is very expensive and where a few big players effectively 'bid' for customers. In these companies, attrition prediction and management is sharply focused. There is typically a strong, welltrained and experienced retention or 'save' team in the contact centre, properly scripted and targeted. They have high incentives to reduce customer attrition, and contactcentre management is strongly focused on containing staff attrition, as inexperienced agents do not manage unhappy or wouldbe departing customers as well as experienced agents. The problem with this approach is that it may result in sub- optimisation. This can occur by too early escalation, for example of customers who were definitely or probably not going to leave, customer incentives that only lead to short-term saves, for example discounts, or the saving of 'wrong' customers, for example those who are unprofitable or troublesome. Outsourced contact-centre services are used to focus on critical areas, to learn, to add capacity at difficult times, for example of price or product change, and sometimes to extend markets.

The professional is common in monoline/direct-only businesses (eg mail order). Their marketing plan balances retention, acquisition and development, with clear and shared accountability for each — in other words, customer management is a team effort and a result of balance between the three areas of focus. There is a good definition of the segments that need retention focus, and there is a correspondingly strong focus on retention in the contact centre, through strategy, targets, propositions, scripts, training and motivation. Testing is used to ensure that contact-centre investments achieve a good return, through retaining the right customers and developing longer term value. These companies constantly seek improvement and never consider their approach perfect, even if that is what 'developers' would give their eye-teeth for. That is because professionals are competing with other professionals, and so must be better than them at retention. Where outsourced contact-centre suppliers are used, it is for focus on critical areas (eg new products and services), to learn and to add capacity at difficult times (eg price/product change).

\section{CONCLUSIONS}

Our conclusions, from a review of this research, are that there are some important areas of focus for companies that want to improve customer retention through 
and by those who create and use data in contact centres;

- developing and implementing relevant performance measures, including customer and workforce optimisation;

- using robust technology, testing it wherever possible, and seeing it in action before buying it;

- having a strong process for identifying gaps and quality problems, closing the gaps and managing the problems and

- recruiting the right people and the right suppliers to deliver improved customer management.

\section{Reference}

1 Stone, M., Aspinall, E. and Nancarrow, C. (2001) 'The meaning \& measurement of customer retention', Journal of Targeting, Measurement \& Analysis for Marketing, Vol. 10, No. 1, pp. 79-87. 